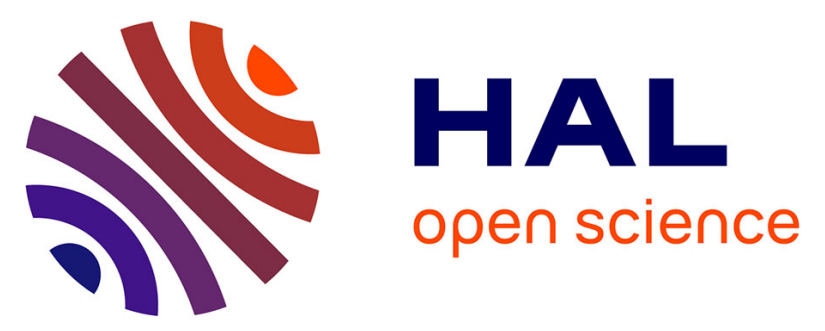

\title{
Impaired intestinal barrier integrity in the colon of patients with irritable bowel syndrome: involvement of soluble mediators.
}

Thierry Piche, Giovanni Barbara, Philippe Aubert, Stanislas Bruley Des

Varannes, Raffaella Dainese, Jean-Louis Nano, Cesare Cremon, Vincenzo

Stanghellini, Roberto de Giorgio, Jean Paul Galmiche, et al.

\section{To cite this version:}

Thierry Piche, Giovanni Barbara, Philippe Aubert, Stanislas Bruley Des Varannes, Raffaella Dainese, et al.. Impaired intestinal barrier integrity in the colon of patients with irritable bowel syndrome: involvement of soluble mediators.. Gut, 2009, 58 (2), pp.196-201. 10.1136/gut.2007.140806 . inserm00332066

\section{HAL Id: inserm-00332066 https://www.hal.inserm.fr/inserm-00332066}

Submitted on 20 Oct 2008

HAL is a multi-disciplinary open access archive for the deposit and dissemination of scientific research documents, whether they are published or not. The documents may come from teaching and research institutions in France or abroad, or from public or private research centers.
L'archive ouverte pluridisciplinaire HAL, est destinée au dépôt et à la diffusion de documents scientifiques de niveau recherche, publiés ou non, émanant des établissements d'enseignement et de recherche français ou étrangers, des laboratoires publics ou privés. 
Impaired intestinal barrier integrity in the colon of irritable bowel syndrome patients: involvement of soluble mediators

T Piche (1-4), G Barbara (5,6), P Aubert (1-3), S Bruley des Varannes (1-3), R Dainese (4), JL Nano (4), C Cremon (5,6), V Stanghellini (5,6), R De Giorgio $(5,6)$, JP Galmiche (1-3), M Neunlist (1-3)

1) INSERM, U913, Nantes, F-44093, France

2) Université de Nantes, Faculté de Médecine, Nantes, F-44093, France

3) CHU Nantes, Hôtel Dieu, Institut des Maladies de l'Appareil Digestif, Nantes, F-44093, France

4) Service de Gastroentérologie \& Inserm U526, Pôle digestif médicochirurgical, Hôpital de l'Archet II, Nice, France.

5) Department of Internal Medicine and Gastroenterology, University of Bologna, Bologna, Italy.

6) CRBA, Centro Unificato di Ricerca BioMedica Applicata, St.Orsola Hospital, Bologna, Italy.

Running Title: Impaired permeability in IBS: role of soluble mediators

Corresponding author:

Michel NEUNLIST

INSERM U 913

Hôpital Hôtel Dieu 1, place Alexis Ricordeau, 44035 NANTES

Tél: ++ 33 (0)2 40087515

Fax: ++ $33(0) 240087506$

E-mail: michel.neunlist@univ-nantes.fr

Word Count: 3499

Abbreviations: IBS; irritable bowel syndrome, IEB; intestinal epithelial barrier, TJs; tight junctions, ZO; zonula occludens, SUP; supernatant, TER; transepithelial resistances.

Key Words: IBS, paracellular permeability, abdominal pain, tight junctions, human colon Licence for Publication

"The Corresponding Author has the right to grant on behalf of all authors and does grant on behalf of all authors, an exclusive licence (or non exclusive for government employees) on a worldwide basis to the BMJ Publishing Group Ltd and its Licensees to permit this article (if accepted) to be published in Gut editions and any other BMJPGL products to exploit all subsidiary rights, as set out in our licence(http://gut.bmijournals.com/ifora/licence.dtl)."

Competing Interest: None to declare. 


\begin{abstract}
Background: Growing evidences suggest that patients with irritable bowel syndrome (IBS) have increased intestinal permeability. In addition, mucosal soluble mediators are involved in the pathophysiology of pain in IBS. We aimed to investigate: (1) paracellular permeability in colonic biopsies of IBS patient (2) the ability of soluble factors from colonic biopsies to reproduce in vitro these alterations. Methods: Paracellular permeability was measured in colonic biopsies of IBS patients and healthy subjects mounted in Ussing chambers. Cleared supernatant (SUP) of culture from colonic biopsies was collected and applied to Caco-2 cells for $48 \mathrm{~h}$. Paracellular permeability and transepithelial resistance (TER) were evaluated. mRNA expression of the tight junction (TJ) proteins, zonula occludens (ZO)-1 and occludin, was assessed in colonic biopsies. Abdominal pain was assessed using a validated questionnaire. Results: Permeability of colonic biopsies was significantly higher in IBS compared to healthy subject. These changes were associated with significantly lower expression of ZO-1 mRNA in biopsies of IBS as compared to healthy subjects. Compared to healthy subjects, SUP of IBS markedly reduced TER and significantly increased permeability in Caco-2 cells. SUP of IBS patients induced a significant decrease of ZO-1 mRNA in Caco-2 as compared to healthy subjects. SUP-induced increased paracellular permeability correlated with the severity of abdominal pain. Conclusions: Our study shows that colonic soluble mediators are able to reproduce functional (permeability) and molecular (ZO-1 mRNA expression) alterations observed in IBS patients. These findings might pave the way both to identify novel biomarkers as well as new therapeutic targets in IBS.
\end{abstract}

\title{
Introduction
}

The irritable bowel syndrome (IBS) is characterized by abdominal discomfort or pain and changes in bowel habit in the absence of an identifiable disease process (1). Currently, the symptoms of IBS involve interactions among central nervous system component, peripheral dysfunction and low-grade inflammation and/or previous intestinal infection (2). In addition to this classical view, emerging evidences suggest that other factors, including altered intestinal permeability, can contribute to IBS and related symptoms (3). Intestinal permeability exerts a key role in the interplay between host and external environment. The paracellular permeability of the intestinal epithelial barrier (IEB) is regulated by a complex protein system that constitute tight junctions (TJs). TJs are composed of the transmembrane proteins occludin and claudins that interact with the zonula occludens (ZO) proteins which bind to the actin cytoskeleton to control paracellular permeability $(4,5)$.

Recent studies have shown that an IBS subgroup present with an increased intestinal permeability $(6,7,8)$. However, conflicting results between post-infectious and unselected IBS patients have been reported $(6,7)$. In one recent study, small intestinal permeability was increased in unselected diarrhoea-predominant and post-infectious IBS as compared to constipation-predominant IBS (8). Furthermore, a recent study has demonstrated that colonic soluble factors contained in faecal homogenates of IBS patients with predominance of diarrhoea increased paracellular permeability in mice (9). However, whether paracellular permeability is altered in the colon of IBS patients remains unknown.

Soluble mediators released by the intestinal mucosa of IBS patients could also play a role in painful symptoms generation. Indeed, recent investigations have shown that soluble factors released from biopsies or from the colonic lumen of IBS patients could induced in vivo visceral hyperalgesia $(9,10,11)$. These effects were shown to be mediated via the release of various mediators such as histamine or tryptase $(9,10,11)$. Furthermore, the effect of soluble factors upon visceral hypersensitivity could be the result of an increase in paracellular permeability induced by these factors (9). However, whether soluble factors can directly modify paracellular permeability of the IEB remains currently unknown. 
Therefore, we aimed to investigate: (1) paracellular permeability in colonic biopsies of IBS patients; (2) the ability of soluble factors from colonic biopsies to reproduce in vitro alterations of IEB integrity.

\section{Material and Methods}

Subjects

Consecutive patients who met the Rome II criteria for IBS (1) were seen in the Department of Internal Medicine and Gastroenterology of the University of Bologna and the Department of Gastroenterology of the Centre Hospitalier Universitaire de Nice. Healthy subjects were recruited by public advertisement after thorough exclusion of gastrointestinal symptoms. None were taking anti-inflammatory drugs (including mast cell stabilizers, histamine antagonists, anticholinergics, anti-diarrhoea medication, probiotics, immunosuppressants, and steroids) or had any organic syndrome, including food allergy, coeliac disease, atopy and severe clinical depression or anxiety. Smoking habits of healthy subject or IBS patients were not recorded. They all gave written informed consent, and the study was approved by the two local Ethical Committees (Bologna and Nice) and conducted in accordance with the Declaration of Helsinki.

Patients were asked to score frequency and severity of symptoms over the last 2 weeks before interview according to previously validated questionnaires (12). The severity of abdominal pain/discomfort was scored 0-4 according to its impact on patients' daily activities: 0 , absent; 1, mild (not influencing activities); 2, relevant (diverting from, but not urging modification of activities); 3 , severe (influencing activities markedly enough to urge modifications); 4, extremely severe (precluding daily activities). The frequency of abdominal pain/discomfort was graded 0-4 according to the following scale: 0 , absent; 1 , up to 1 day/week; 2, 2 or 3 days/week; 3, 4-6 days per week; 4, daily. All clinical interviews were done within two weeks before the colonoscopy.

\section{Collection and assay of mucosal mediators}

A left colonoscopy without sedation was performed in participants after cleansing of distal colon with two 500-mL water enemas performed before the procedure. For all participants, 2 mucosal biopsies were obtained for routine $H \& E$ histology to exclude the presence of microscopic colitis. One biopsy was placed in Eppendorf RNAse free tubes, snap frozen in liquid nitrogen, and maintained at $-70^{\circ} \mathrm{C}$. Upon removal, 2 other biopsies were rapidly immersed in hard plastic tubes containing $1 \mathrm{ml}$ of Hank's buffer saline solution (HBSS, Invitrogen, Cergy-Pontoise, France), continuously oxygenated $\left(95 \% \mathrm{O}_{2} / 5 \% \mathrm{CO}_{2}\right)$ at $37^{\circ} \mathrm{C}$. After $20 \mathrm{~min}$ incubation, the solution was removed and centrifugated at $200 \mathrm{~g}$ for 10 min before being filtered with centrifuge tube filters $(0.22 \mu \mathrm{m}$, SPIN-X, Corning, NY, USA) to remove bacterial components. Aliquots of $200 \mu \mathrm{l}$ of supernatant (SUP) were stored at $70^{\circ} \mathrm{C}$ until assays. Biopsies were blotted and weighted after collecting the SUP. In 13 IBS patients and 5 healthy subjects, 4 biopsies were taken for the purpose of paracellular permeability as described below. None of these subjects were smokers.

\section{Paracellular permeability of colonic biopsies in Ussing chambers}

Paracellular permeability in colonic biopsies was measured as previously described (13). Four standard biopsies were mounted in adapted Ussing chambers (Transcellab, TBC, Paris, France) exposing a surface of $0.0314 \mathrm{~cm}^{2}$. Tissues were bathed on each side with $3 \mathrm{~mL}$ of Ham's Nutrient Mixture (HAM's F12, Invitrogen, France). The medium was continuously oxygenated and maintained at $37^{\circ} \mathrm{C}$ by a gas flow $\left(95 \% \mathrm{O}_{2}, / 5 \% \mathrm{CO}_{2}\right)$. After a 15 min baseline period, $150 \mu \mathrm{l}$ of apical medium was replaced by $150 \mu \mathrm{l}$ of fluorescein-5.6 sulfonic acid (10 $\mathrm{mg} / \mathrm{mL})(400 \mathrm{D}$, Invitrogen, France). The fluorescence level of basolateral aliquots of $150 \mu \mathrm{l}$ was measured at $30 \mathrm{~min}$ interval during $180 \mathrm{~min}$ using a fluorimeter (Tecan Infinite F500, 
Tecan SA, France). Fluorescence values were converted in concentrations of fluorescein $(\mathrm{ng} / \mathrm{mL})$ using a standard curve. Values of permeability at 180 min were the mean of 4 biopsies with individual coefficient of variability less than $5.2 \%$.

Caco-2 cells

Experiments were performed with the human intestinal epithelial cell lines Caco-2 (EATCC, Port Down, UK). Cells were seeded onto porous filters (12-well Transwell Clear, $0.40 \mu \mathrm{m}$ porosity, $1.1 \mathrm{~cm}$ of diameter, Corning, ATGC, Marne la Vallée, France), at a density of 200,000 cells/filter and cultured in DMEM (4.5 g/l glucose; Invitrogen) supplemented with $10 \%$ heat-inactivated FCS (Abcys, Paris, France), $2 \mathrm{mM}$ glutamine (Invitrogen) and $50 \mathrm{IU} / \mathrm{ml}$ penicillin, and $50 \mu \mathrm{g} / \mathrm{ml}$ streptomycin (Invitrogen). After 14 days of culture, Caco-2 cells formed differentiated and polarised monolayer. The culture medium was changed every 2 days.

\section{Experimental protocol}

Caco-2 cell monolayers were incubated for 48 hours with SUP of healthy subjects or IBS patients. The SUP was added onto the apical and basolateral side of Caco- 2 monolayers. The volume of SUP was normalized to the weight of biopsies $(150 \mu 1 \mathrm{for} 5 \mathrm{mg})$ in order to add similar concentrations of soluble mediators (e.g. SUP was diluted once the biopsy weight was known). Control solutions were also performed by adding similar volumes of HBSS than SUP.

\section{Resistances and paracellular permeability of Caco-2 cells}

Caco-2 monolayer transepithelial resistances (TER) were measured with an epithelial volt-ohmmeter (WPI, Stevenage, UK) before and after 24 and 48 hours incubation with SUP. Results $(\Omega)$ are presented as differences compared to basal values.

Paracellular permeability studies were performed using the flux of Dextran-FITC through Caco-2 monolayer as previously described (14). At the end of the 48 hours incubation period, $150 \mu \mathrm{L}$ of FITC-conjugated dextran $(4 \mathrm{kDa}, 10 \mathrm{mg} / \mathrm{mL}$; Sigma, Saint Quentin Fallavier, France) were added to the apical compartment. Basolateral aliquots were taken after 8 hours and the fluorescence level was measured in a 96-wells fluorescent plate reader using a fluorimeter at $496 \mathrm{~nm}$ (PerkinElmer, Courtaboeuf, France). Values were converted in concentrations of FITC dextran $(\mathrm{ng} / \mathrm{mL})$ using a standard curve.

ZO-1 and occludin mRNA expression by real-time quantitative polymerase chain reaction $(R T-q P C R)$

Total RNA was extracted from cells using RLT (Qiagen, Courtaboeuf, France) according to the manufacturer's instructions. Total RNA $(5 \mu \mathrm{g}), \mathrm{pd}(\mathrm{N})_{6}$ random hexamers $(1 \mu 1,265 \mathrm{ng} / \mu \mathrm{l})(\mathrm{GE}$ Healthcare, Orsay, France) dNTPs $(1 \mu 1,10 \mathrm{mM})$ (Invitrogen), first strand buffer 5X ( $5 \mu \mathrm{l})$ (Invitrogen), DDT (1 $\mu 1,0,1 \mathrm{M})$ (Invitrogen), and RNasin $(0,5 \mu 1,40 \mathrm{U} / \mu \mathrm{l})$ (Promega, Charbonnieres, France) were used to synthesize single-stranded cDNA using the Superscript II Reverse Transcriptase (Invitrogen; 0,5 $\mu 1,200 \mathrm{U} / \mu \mathrm{l}$ ) in a total volume of $25 \mu \mathrm{l}$. Incubation was performed at $42^{\circ} \mathrm{C}$ for $60 \mathrm{~min}$. Amplification conditions for S6 (house keeping gene), ZO-1 and occludin were optimized for the RotorGene 2000 instrument (Ozyme, Saint Quentin en Yvelines, France). PCRs were performed with $2 \mu \mathrm{l}$ of cDNA, $0.1 \mu \mathrm{l}$ of a solution of SYBR Green I diluted at $1: 100$ (Sigma), $1 \mu 1(10 \mu \mathrm{M})$ of each primer, $1 \mu \mathrm{l}(10$ $\mathrm{mM}$ ) dNTPs, and $0,4 \mu \mathrm{l}$ of Titanium Taq DNA polymerase kit (Ozyme). Cycling conditions were as follows: $5 \mathrm{~min}$ at $95^{\circ} \mathrm{C}$; amplification for 40 cycles, with denaturation for $5 \mathrm{~s}$ at $95^{\circ} \mathrm{C}$, annealing for $15 \mathrm{~s}\left(66^{\circ} \mathrm{C}\right.$ for $\mathrm{S} 6$ and $\left.\mathrm{ZO}-1\right),\left(68^{\circ} \mathrm{C}\right.$ for Occludin) and extension for $15 \mathrm{~s}$ at $72^{\circ} \mathrm{C}$. The following primers were used: 
S6 forward 5'- CCAAGCTTATTCAGCGTCTTGTTACTCC-3'; S6 reverse 5'CCCTCGAGTCCTTCATTCTCTTGGC -3' (PCR product $130 \mathrm{pb}$ );

ZO-1 forward 5'- GAATGATGGTTGGTATGGTGCG -3'; ZO-1 reverse 5'TCAGAAGTGTGTCTACTGTCCG -3' (PCR product $191 \mathrm{pb}$ );

Occludin forward 5'- ATGAGACAGACTACACAACTGG -3';

Occludin reverse 5'- TTGTATTCATCAGCAGCAGC -3' (PCR product $252 \mathrm{pb}$ ).

All PCR products were sequenced to validate the specificity of the amplification.

An external standard curve was generated with serial dilutions of control cDNA, by plotting the relative amounts of these dilutions against the corresponding $\mathrm{C}_{t}$ (threshold cycle) values. The amount of ZO-1, occludin and S6 was calculated from these standard curves using the RotorGene software (Ozyme). Samples were tested in triplicate and the average values were used for quantification using the $2^{-\Delta \Delta \mathrm{CT}}$ method as previously described (15).

\section{Pharmacological tools}

Histamine (Sigma) was added to the apical and basolateral compartment of Caco-2 monolayer at a final concentration of $10 \mu \mathrm{M}$. Chlorpheniramine (histamine-1 receptor antagonist, Sigma), Cimetidine (histamine-2 receptor antagonist, Sigma) and Thioperamide (histamine-3/4 receptor antagonist, Sigma) were used at the following final concentrations dissolved in sterile water, $10^{-5} \mathrm{M}, 10^{-4} \mathrm{M}$ and $10^{-6} \mathrm{M}$, respectively. Differentiated Caco-2 monolayers were first treated during $30 \mathrm{~min}$ with a cocktail of histamine receptor antagonists, prior to the addition of SUP of both healthy subjects and IBS patients for 48 hours.

\section{Statistical analysis}

Data were expressed as mean $\pm \mathrm{SD}$ or median and interquartile ranges and were compared using non-parametric Mann Whitney $U$ test or ANOVA with post-tests when appropriate. Relationships between permeability and TER, abdominal pain severity and TJs expression were assessed by linear regression. A $p$ value $<0.05$ was considered significant.

\section{Results}

Fifty one IBS patients and fourteen healthy subjects were included in the study. The clinical characteristics of IBS patients are described in Table 1 according to IBS subtypes.

\section{Paracellular permeability of colonic biopsies}

Paracellular permeability of colonic biopsies at $180 \mathrm{~min}$ of culture was significantly higher in IBS patients $(107 \pm 30 \mathrm{ng} / \mathrm{mL}, \mathrm{n}=12)$ compared with healthy subjects $(66 \pm 5 \mathrm{ng} / \mathrm{mL}$, $\mathrm{n}=5, p=0.01$ ). There was no difference among IBS subtypes (Figure 1). In IBS patients, a statistical trend was observed between the severity of abdominal symptoms and paracellular permeability of colonic biopsies $(\mathrm{r}=0.55, p=0.06)$. However, no correlation was found between the frequency of abdominal pain and paracellular permeability.

\section{ZO-1 and occludin expression in colonic biopsies}

ZO-1 mRNA expression was significantly lower in biopsies of IBS patients compared to healthy subjects $(1.2 \pm 2.0$ vs $14.0 \pm 28.8, p=0.04)$ (Figure 2A). Occludin mRNA expression was similar between IBS patients and healthy subjects $(17.5 \pm 36$ vs $14 \pm 25, p=0.7)$ (Figure 2B). There was an inverse correlation between the expression of ZO-1 mRNA expression in colonic biopsies and the paracellular permeability induced in Caco- 2 by SUP of the corresponding IBS patient $(\mathrm{r}=-0.56, p=0.01)$.

Effect of SUP on TER and paracellular permeability of Caco-2 cells 
After forty-eight hours, SUP of IBS induced a significant fall in TER of Caco-2 monolayer $(-100 \pm 66 \Omega, \mathrm{n}=39)$ compared to that of healthy subjects $(-9 \pm 32 \Omega, \mathrm{n}=14$ $\mathrm{p}<0.0001)$ and control solutions $(-13 \pm 37, \mathrm{n}=12 \mathrm{p}<0.0001)$ (Figure 3$)$. Interestingly, changes in TER were similar among IBS subtypes at any time-points (data not shown). SUP of IBS patients applied to Caco-2 cells induced a significant increase of paracellular permeability $(1218 \pm 265 \mathrm{ng} / \mathrm{mL}, \mathrm{n}=39)$ compared to SUP of healthy subjects $(989 \pm 117 \mathrm{ng} / \mathrm{mL}, \mathrm{n}=14$, $p=0.001)$ and control solutions $(1042 \pm 121 \mathrm{ng} / \mathrm{mL}, \mathrm{n}=12, p=0.01)$ (Figure 4). In IBS patients, there was a significant inverse correlation between paracellular permeability and changes in TER ( $\mathrm{r}=-0.63, p<0.0001)$. Paracellular permeability was similar among IBS subtypes (Figure 4).

In IBS patients, the severity of abdominal pain was significantly associated with paracellular permeability (Figure 5). This correlation was more stringent in IBS patients with predominance of diarrhoea $(\mathrm{r}=0.65, p=0.01)$ than in patients with predominance of constipation $(\mathrm{r}=0.56, p=0.02)$. However, no correlation was found in IBS patients with alternating symptoms. In addition, the frequency of abdominal pain was not correlated with paracellular permeability in IBS patients. Paracellular permeability and the severity of abdominal pain were not associated with age or gender of patients.

\section{Effect of SUP on ZO-1 and occludin expression on Caco-2 cells}

ZO-1 mRNA expression was significantly lower in Caco-2 incubated with SUP of IBS patients than with SUP of healthy subjects $(1.6 \pm 2.4$ vs $10.3 \pm 16.0, p=0.01)$ (Figure 6A). In contrast, the expression of occludin mRNA was similar between IBS patients and healthy subjects (Figure 6B). There was no difference between IBS subtypes. A trend to an inverse correlation was observed between the expression of ZO-1 mRNA in Caco-2 cells and paracellular permeability in IBS patients $(\mathrm{r}=-0.35, p=0.09)$. In addition, no change was observed in the pericellular distribution of ZO-1 in Caco-2 monolayers incubated with SUP of IBS or healthy subjects (data not shown).

\section{Effect of histamine and receptor antagonists on TER and paracellular permeability of Caco-2} cells

Compared to control solution, changes in TER were not modified after addition of histamine $(10 \mu \mathrm{M})$ to Caco-2 cells for 16 hours as compared to control (57.6 \pm 23.7 vs. $40.0 \pm 52.6 \Omega, \mathrm{n}=6, p=0.4)$. In addition, histamine did not altered significantly paracellular permeability of Caco- 2 cells compared to control solution $(1113 \pm 221$ vs. $1337 \pm 376 \mathrm{ng} / \mathrm{mL}$, $p=0.3$ respectively). Changes in TER and paracellular permeability of Caco- 2 monolayers incubated with SUP of IBS patients $(n=6)$ or healthy subjects $(n=4)$ were not significantly modified by a pre-treatment with a cocktail of histamine receptor antagonists (data not shown).

\section{Discussion}

The current study showed that paracellular permeability of colonic biopsies of IBS patients is increased irrespective of IBS subtypes. Moreover soluble mediators released from colonic biopsies of IBS patients induced a significant increase in the paracellular permeability of Caco-2 cell monolayers as compared to healthy subjects. Of interest, the magnitude of increase in permeability was positively correlated with abdominal pain severity of IBS patients. In addition, SUP of IBS patients induced a concomitant decrease in ZO-1 but not occludin mRNA expression in Caco-2 as compared to healthy subjects. A similar significant decrease in ZO-1, but not occludin, mRNA expression was also observed in colonic biopsies of IBS patients as compared to healthy subjects. In our experiments, the role of histamine as a candidate mediator is unlikely. 
A growing body of evidence suggests that disturbances of IEB functions, in particular enhanced gut permeability, may play a contributory role in the sequence leading to gut dysfunction and generation IBS symptoms. Indeed, using the lactulose/mannitol test, elevated intestinal permeability has been documented in 12 to $50 \%$ of IBS patients, depending on the infective nature of IBS, inclusions of patients with adverse reaction to food or various IBS criteria (7, 16-19). More recently, Dunlop et al. (8) found highest small bowel permeability in non post-infectious compared to post-infectious IBS or healthy subjects, and in IBS with predominance of diarrhoea compared to IBS with predominance of constipation and healthy subjects. Our study extents previous findings of increased permeability detected in the small intestine of IBS patients to the colon by showing that 1) paracellular permeability is also increased in the human colon of IBS patients and 2) in contrast to the small intestine, this increase (observed in colonic biopsies and also induced by soluble factors from biopsies) is independent of IBS subtypes. Interestingly, this latter finding is in contrast with the data of Gecse et al. (9) who showed that only SUP of IBS patients with predominance of diarrhea bowel habit could increase paracellular permeability. These differences could result from the fact that alterations of paracellular permeability described by Gecse et al. (9) were observed following acute administration of SUP (1h), whereas we performed a more prolonged administration of SUP (48h). This point also further justified the use of transformed intestinal epithelial cell lines as they can survive for long time in contrast to mucosal biopsies which showed functional alterations as early as 4 to 6 hours (20). Another important finding was that changes of paracellular permeability was related to a direct effect of SUP upon intestinal epithelial cells. Indeed, integrated studies performed in vivo/ex vivo cannot excluded that effects of SUP upon permeability were mediated via the activation of other cells from the mucosa such as nerves or immune cells which are known to control IEB functions (for review, see 21). This is of particular interest in attempt to identify new biomarkers for therapeutic intervention in IBS. Indeed, alterations of ZO-1 expression that we observed in colonic biopsies or that were induced by SUP in caco- 2 cells could be a direct marker of IEB dysfunction in IBS.

The causes underlying pain in IBS are still poorly understood. Enhanced permeability has been suggested as an etiologic factor in several inflammatory conditions associated with pain, including Crohn's disease (22), coeliac disease (23) and acute gastroenteritis (24). A cause-effect relationship between mucosal barrier alterations and visceral hypersensitivity has been described in a recent animal study in which the chemical blockade of enhanced colonic paracellular permeability induced by stress was accompanied by a decrease sensitivity to colonic distension (25). Our present findings suggest that the correlation between paracellular permeability and pain scores of IBS patients could be related to the effect of soluble mediators released from biopsy specimens. Interestingly, similar findings were obtained using colonic biopsies of IBS patients. It has been recently demonstrated that IBS patients had a marked increase in colonic mucosal area occupied by mast cells with increased release of histamine and tryptase compared to healthy subjects (12). Moreover, the severity of abdominal pain of IBS patients was directly related to the proximity between activated mast cells and mucosal nerves (12).

Our study also suggests a molecular basis for the SUP-induced increase in permeability, involving the TJs complex. Indeed, SUP of IBS patients, but not of healthy subjects, induced a significant reduction in ZO-1 mRNA expression in Caco-2 cells. Interestingly, a significant decrease of ZO-1 mRNA expression was also observed in colonic biopsies of IBS patients but not of healthy subjects. Finally, there was a trend of inverse correlation between ZO-1 mRNA expression in Caco-2 monolayers and paracellular permeability and a strong significant inverse correlation between these parameters in colonic biopsies of IBS patients. All these findings indicate that mediators released from colonic biopsies of IBS patients could increase permeability by altering the expression of TJ proteins, in particular ZO-1. This observation is 
in agreement with the role of ZO-1 in the control of paracellular permeability. Indeed, various factors known to reduce permeability have been shown to increase ZO-1 expression both at the mRNA and protein level $(13,14)$. Similarly, in diseases with increased permeability a reduction of ZO-1 expression and mRNA has also been observed (26). Whether the reduction of mRNA expression is associated with decreases of ZO-1 proteins remains unknown. Measurements of ZO-1 mRNA expression in biopsies of IBS patients could be used as a marker of the alteration in the IEB permeability. Indeed, we found an inverse correlation between ZO-1 mRNA expression in biopsies and permeability changes of Caco-2 induced by SUP coming from same patients.

Mediators released by biopsies responsible for the effects on IEB still remain to be identified. Previous studies $(10,11)$ have shown that candidates such as protease and histamine are involved in the effects of SUP of IBS upon the neuronal excitability. In our study, we choose first to explore the role of histamine because of its well-known involvement in the secretory response of the IEB in diseases such as allergy and inflammatory bowel diseases $(27,28)$. Histamine also induces a secretory response in a human intestinal epithelial cell line and in mouse distal colon (29). However, the in vitro effects of histamine and/or various types of histamine receptor antagonists on paracellular permeability have lead to controversial findings, depending on the type of cell line and designs of studies (30-33). Our data suggest that histamine has no effect upon the regulation of the IEB paracellular permeability in vitro. Taken together, these data suggest that histamine could be involved in the increased viscerosensitivity in IBS, but not in the increased paracellular permeability. Finally, a recent study has shown that SUP of IBS increases paracellular permeability via activation of PAR-2 receptors (9). Whether such pathways are involved in our observations are the focus of ongoing studies.

In conclusion, these data suggest that alterations of the integrity of IEB are present in colonic biopsies of IBS patients. Soluble mediators from colonic biopsies are involved in these alterations by affecting TJs expression. These findings suggest that agents aimed at reinforcing IEB function could be a novel therapeutical target in IBS.

\section{Acknowledgements}

The study was supported by grants of Sanofi-Aventis and a "Programme Hospitalier de Recherche Clinique 2007-2008" of the CHU of Nice". The study was also supported by the Italian Ministry of Education, University and Research (No. 2002052573, to G.B., V.S., R.De.G.), and R.F.O. from the University of Bologna (to G.B., R.DeG., V.S.). 


\section{References}

1. Thompson WG, Longstreth GF, Drossman DA, et al. Functional bowel disorders and functional abdominal pain. Gut 1999;45(Suppl 2):S43-S47.

2. Collins SM, Piche T, Rampal P. The putative role of inflammation in the irritable bowel syndrome. Gut 2001;49:743-5.

3. Barbara G. Mucosal barrier defects in irritable bowel syndrome. Who left the door open? Am J Gastroenterol 2006;101:1295-8.

4. Nusrat A, Turner JR, Madara JL. Molecular physiology and pathophysiology of tight junctions.IV. Regulation of tight junctions by extracellular stimuli: nutrients, cytokines, and immune cells. Am J Physiol Gastrointest Liver Physiol 2000;279:G851-7.

5. Tsukita S, Furuse M, Itoh M. Structural and signaling molecules come together at tight junctions. Curr Opin Cell Biol 1999;11:628-3.

6. Spiller RC, Jenkins D, Thornley JP, et al. Increased rectal mucosal enteroendocrine cells, T lymphocytes, and increased gut permeability following acute Campylobacter enteritis and in post-dysenteric irritable bowel syndrome. Gut 2000;47:804-1.

7. Marshall JK, Thabane M, Carg AX, et al. Intestinal permeability in patients with irritable bowel syndrome after a waterborne outbreak of acute gastroenteritis in Walkerton, Ontario. Aliment Pharmacol Ther 2004;20:1317-2.

8. Dunlop SP, Hebden J, Campbell E, et al. Abnormal intestinal permeability in subgroups of diarrhea-predominant irritable bowel syndromes. Am J Gastroenterol 2006;101:1295-4.

9. Gecse K, Roka R, Ferrier L, et al. Increased faecal serine protease activity in diarrhoeic IBS patients: a colonic lumenal factor impairing permeability and sensitivity. Gut 2008;57:591-8.

10. Cenac N, Andrews CN, Holzhausen M, et al. Role of protease activity in visceral pain in irritable bowel syndrome. J Clin Invest 2007;117:636-7.

11. Barbara G, Wang B, Stanghellini V, et al. Mast cell-dependent excitation of visceralnociceptive sensory neurons in irritable bowel syndrome. Gastroenterology 2007;132:26-37.

12. Barbara G, Stanghellini V, De Giorgio R, et al. Activated mast cells in proximity to colonic nerves correlate with abdominal pain in irritable bowel syndrome. Gastroenterology 2004;126:693-702.

13. Savidge,TC, Newman P, Pothoulakis C, et al. Enteric glia regulate intestinal barrier function and inflammation via release of S-Nitroglutathione. Gastroenterology 2007;132:1344-58.

14. Neunlist M, Toumi F, Oresschkova T, et al. Human ENS regulates the intestinal epithelial barrier permeability and a tight junction-associated protein ZO-1 via VIPergic pathways. Am J Physiol Gastrointest Liver Physiol 2003;285:G1028-G1036.

15. Livak KJ, Schmittgen TD. Analysis of relative gene expression data using real-time quantitative PCR and the 2-DDCt Method. Methods 2001;25:402-408.

16. Spiller RC, Jenkins D, Thornley JP, et al. Increased rectal mucosal enteroendocrine cells, $\mathrm{T}$ lymphocytes, and increased gut permeability following acute Campylobacter enteritis and in post-dysenteric irritable bowel syndrome. Gut 2002;47:804-11.

17. Dainese R, Galliani EA, De Lazzari F, et al. Discrepancies between reported food intolerance and sensitization test findings in irritable bowel syndrome patients. Am $J$ Gastroenterol 1999;94:1892-97.

18. Vogelsang H, Wyatt J, Penner E, et al. Screening for celiac disease in first-degree relatives of patients with celiac disease by lactulose/mannitol test. Am J Gastroenterol 1995;90:1838-42.

19. Barau E, Dupont C. Modifications of intestinal permeability during food provocation procedures in pediatric irritable bowel syndrome. J Pediatr Gastroenterol Nutr 1990;11:72-7. 
20. Wallon C, Braaf Y, Wolving M, et al. Endoscopic biopsies in Ussing chambers evaluated for studies of macromolecular permeability in the human colon. Scand J Gastroenterol 2005;40:586-95.

21. Neunlist M, Van Landeghem L, Boureille A, et al. Neuro-glial crosstalk in inflammatory bowel disease. J Intern Med 2008;263:577-83.

22. Soderholm JD, Peterson KH, Olaison G, et al. Epithelial permeability to proteins in the noninflamed ileum of Crohn's disease ? Gastroenterology 1999;117:65-72.

23. Cobden I, Rothwell J, Axon AT. Intestinal permeability and screening tests for coeliac disease. Gut 1980;21:512-8.

24. Zuckerman MJ, Watts MT, Bhatt BD, et al. Intestinal permeability to (51Cr)EDTA in infectious diarrhea. Dig Dis Sci 1993;38:1651-7.

25. Ait-Belgnaoui A, Bradesi S, Fioramonti J, et al. Acute stress-induced hypersensitivity to colonic distension depends upon increase in paracellular permeability: role of myosin light chain kinase. Pain 2005;113:141-7.

26. Kucharzik T, Walsh SV, Chen J, et al. Neutrophil transmigration in inflammatory bowel disease is associated with differential expression of epithelial intercellular junction proteins. Am J Pathol 2001;159:2001-9.

27. Crowe SE, Luthra GK, Perdue MH. Mast cell mediated transport in intestine from patients with and without inflammatory bowel disease. Gut 1997;41:785-92

28. Xie $\mathrm{H}, \mathrm{He} \mathrm{SH}$. Role of histamine and its receptors in allergic and inflammatory bowel diseases. World J Gastroenterol 2005;21:2851-7.

29. Oprins JC, van der Burg C, Meijer HP, et al. Tumor necrosis factor alpha potentiates ion secretion induced by histamine in a human intestinal epithelial cell line and in mouse colon: involvement of the phospholipase D pathway. Gut 2002;50:314-21.

30. Hirase T, Kawashima S, Wong AYM et al. Regulation of tight junction permeability and occludin phosphorylation by RhoA-p160ROCK-dependant and independent mechanisms. $J$ Biol Chem 2001;276:10423-31.

31. Guo Y, Ramachandran C, Satpathy M, et al. Histamine-induced myosin light chain phosphorylation breaks down the barrier integrity of cultured corneal epithelial cells. Pharm Res 2007;24:1824-33.

32. Devalia JL, Godfrey RW, Sapsford RJ, et al. No effect of histamine on human bronchial epithelial cell permeability and tight junctional integrity in vitro. Eur J Respi 1994;7:1958-65. 33. Gan LS, Souzan Y, Thakker DR. Modulation of the tight junctions of the Caco-2 cell monolayers by $\mathrm{H}_{2}$-antagonists. Pharm Res 1998;15:53-7.

Table 1: Clinical characteristics of IBS patients.

\begin{tabular}{|c|c|c|c|c|}
\hline IBS subtype & IBS-C & IBS-D & IBS-A & $P$ value \\
\hline $\operatorname{Sex}(M / F)$ & $2 / 17$ & $7 / 10$ & $2 / 13$ & - \\
\hline Age (y) & $43.6[22-65]$ & $45.1[19-71]$ & $47.2[20-78]$ & 0.8 \\
\hline $\begin{array}{l}\text { Abdominal pain severity } \\
\text { (mean score and SD) }\end{array}$ & $2.5 \pm 0.8$ & $2.6 \pm 0.9$ & $2.1 \pm 0.8$ & 0.3 \\
\hline $\begin{array}{l}\text { Abdominal pain frequency } \\
\text { (mean score and SD) }\end{array}$ & $2.5 \pm 0.6$ & $2.6 \pm 0.8$ & $2.7 \pm 1.0$ & 0.5 \\
\hline
\end{tabular}

NOTE: IBS-C, predominant constipation; IBS-D, predominant diarrhoea; IBS-A, constipation alternating with diarrhoea. Values in brackets are minimum and maximum. 


\section{Figure Legends}

Figure 1 : Paracellular permeability to FITC-sulfonic acid (expressed in $\mathrm{ng} / \mathrm{mL}$ ) in colonic biopsies of IBS patients $(n=12)$ and healthy subjects $(n=5)$. IBS patients are also shown according to IBS subtypes. IBS-C; predominance of constipation $(n=3)$. IBS-D; predominance of diarrhoea $(\mathrm{n}=4)$, IBS-A; alternating symptoms $(\mathrm{n}=5) .{ }^{*} p<0.05$ vs. healthy subjects. Dotted lines are mean values.

Figure 2: Tight junction proteins (ZO-1 and occludin) mRNA expression in colonic biopsies of IBS patients $(n=21)$ and healthy controls $(n=12)$. Results are medians and interquartile ranges. $* p=0.03 v s$. healthy subjects.

Figure 3: Effect of 48 hours incubation of Caco-2 cells with supernatant of patients with IBS $(n=39)$ and healthy controls $(n=14)$ on the variations of transepithelial resistance $(\triangle$ TER, $\Omega)$ at day 1 and day $2 .{ }^{\mathrm{a}} p=0.01,{ }^{\mathrm{b}} p<0.0001 v s$. healthy subjects. Results are means \pm SD.

Figure 4: Effect of 48 hours incubation of Caco-2 cells with supernatant of patients with IBS $(n=39)$ and healthy controls $(n=14)$ on paracellular permeability to FITC-Dextran of Caco-2 monolayer (expressed in $\mathrm{ng} / \mathrm{mL}$ ). IBS patients are also shown according to IBS subtypes. IBS-C; predominance of constipation $(n=15)$. IBS-D; predominance of diarrhoea $(n=14)$, IBS$\mathrm{A}$; alternating symptoms $(\mathrm{n}=10){ }^{*} p<0.05, * * p<0.01 v s$. healthy subjects. Dotted lines are mean values.

Figure 5: Paracellular permeability of Caco-2 cells as a function of the severity of abdominal pain in 39 patients with IBS. * $p=0.006$.

Figure 6: Effect of 48 hours incubation of Caco-2 cells with supernatant of patients with IBS $(n=23)$ and healthy controls $(n=6)$ on ZO-1 and occludin mRNA expression. Results are medians and interquartile ranges. $* p=0.04$ vs. healthy subjects. 


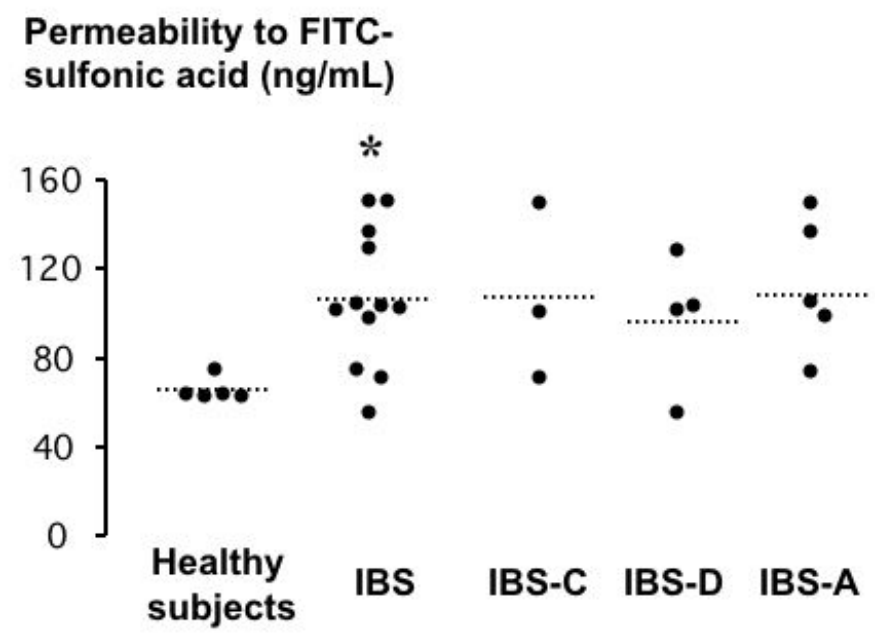

A

ZO-1 mRNA

(arbitrary unit)

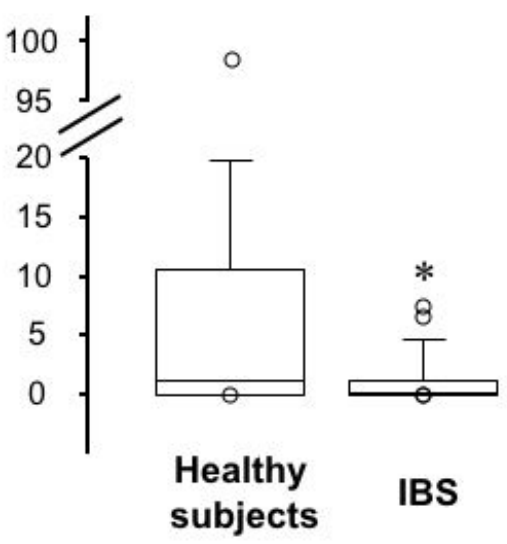

B

Occludin mRNA

(arbitrary unit)

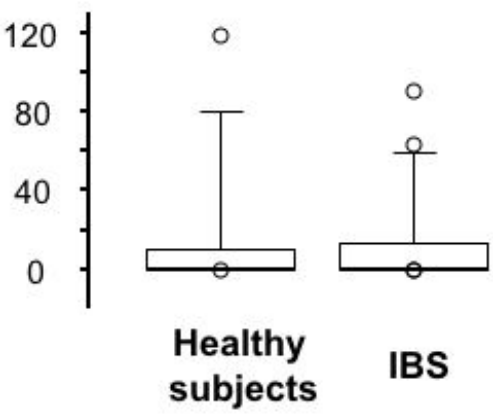




\section{$\Delta \operatorname{TER}(\Omega)$}
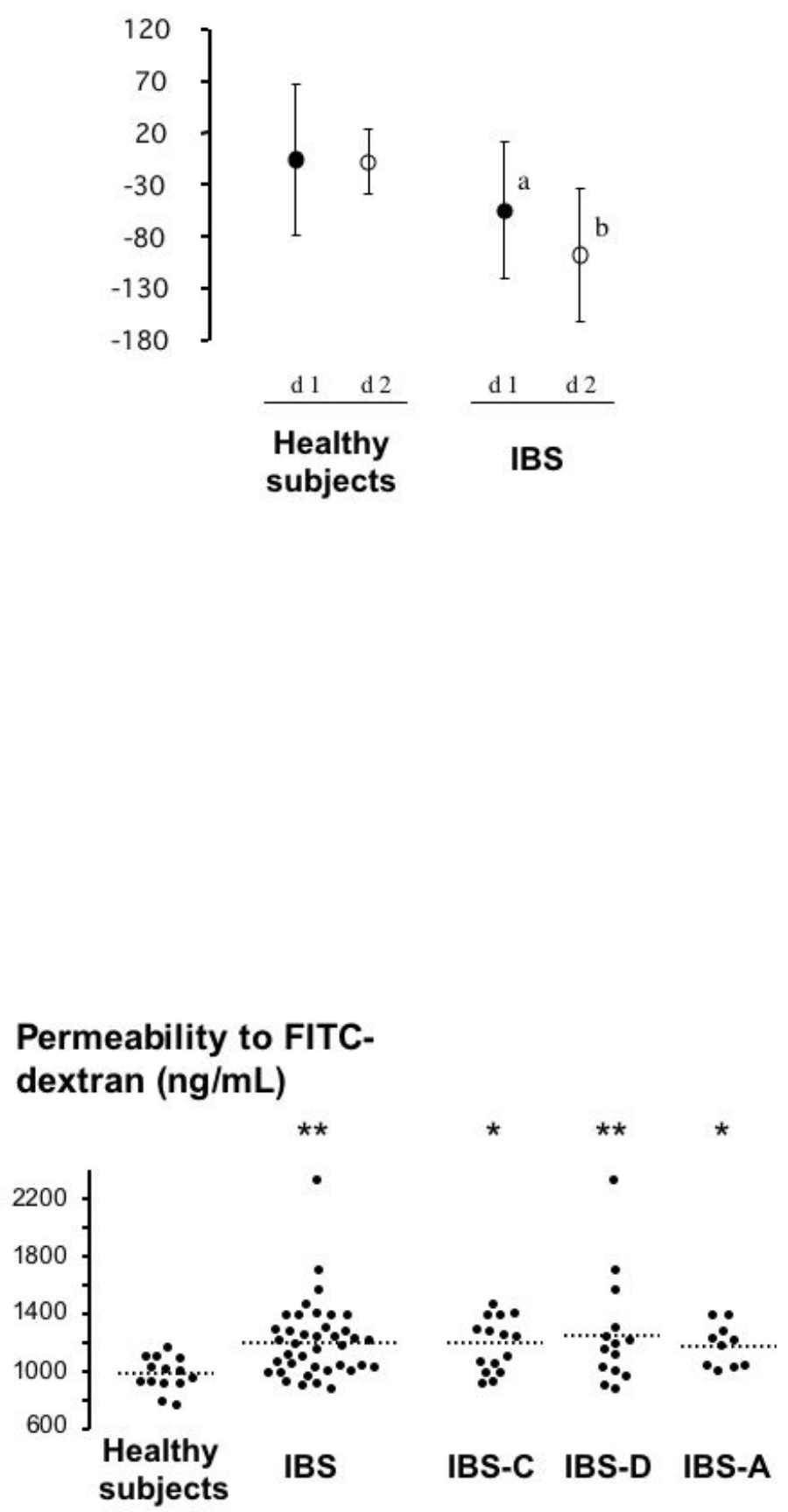


\section{Permeability to FITC- dextran $(\mathrm{ng} / \mathrm{mL})$}

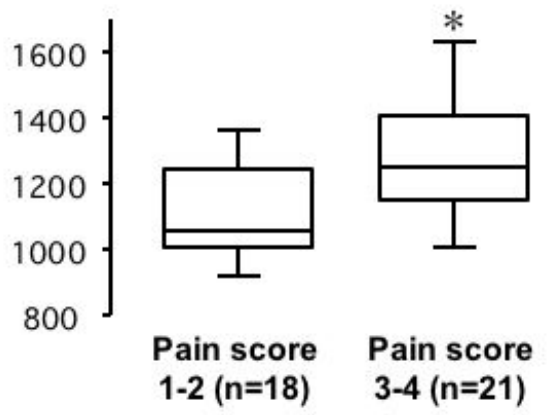

A

ZO-1 mRNA

(arbitrary unit)

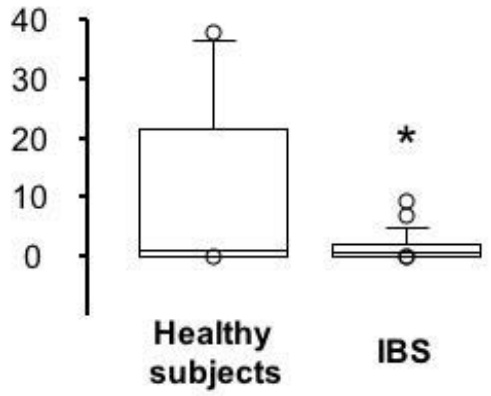

B

Occludin mRNA (arbitrary unit)

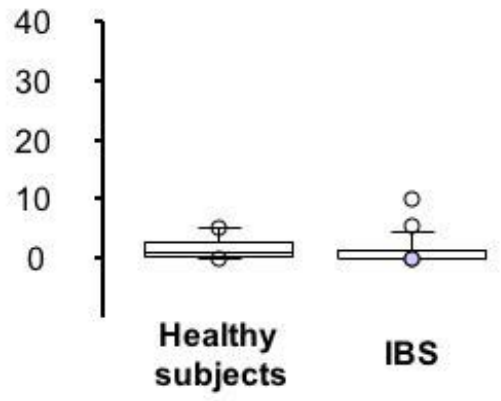

